This item was submitted to Loughborough's Research Repository by the author.

Items in Figshare are protected by copyright, with all rights reserved, unless otherwise indicated.

\title{
Elastohydrodynamics of hypoid gears in axle whine conditions
}

PLEASE CITE THE PUBLISHED VERSION

http://dx.doi.org/10.4271/2012-01-1538

PUBLISHER

(C) SAE International

VERSION

VoR (Version of Record)

LICENCE

CC BY-NC-ND 4.0

REPOSITORY RECORD

Mohammadpour, Mahdi, Stephanos Theodossiades, and Homer Rahnejat. 2019. "Elastohydrodynamics of Hypoid Gears in Axle Whine Conditions". figshare. https://hdl.handle.net/2134/14262. 
This item was submitted to Loughborough's Institutional Repository (https://dspace.lboro.ac.uk/) by the author and is made available under the following Creative Commons Licence conditions.

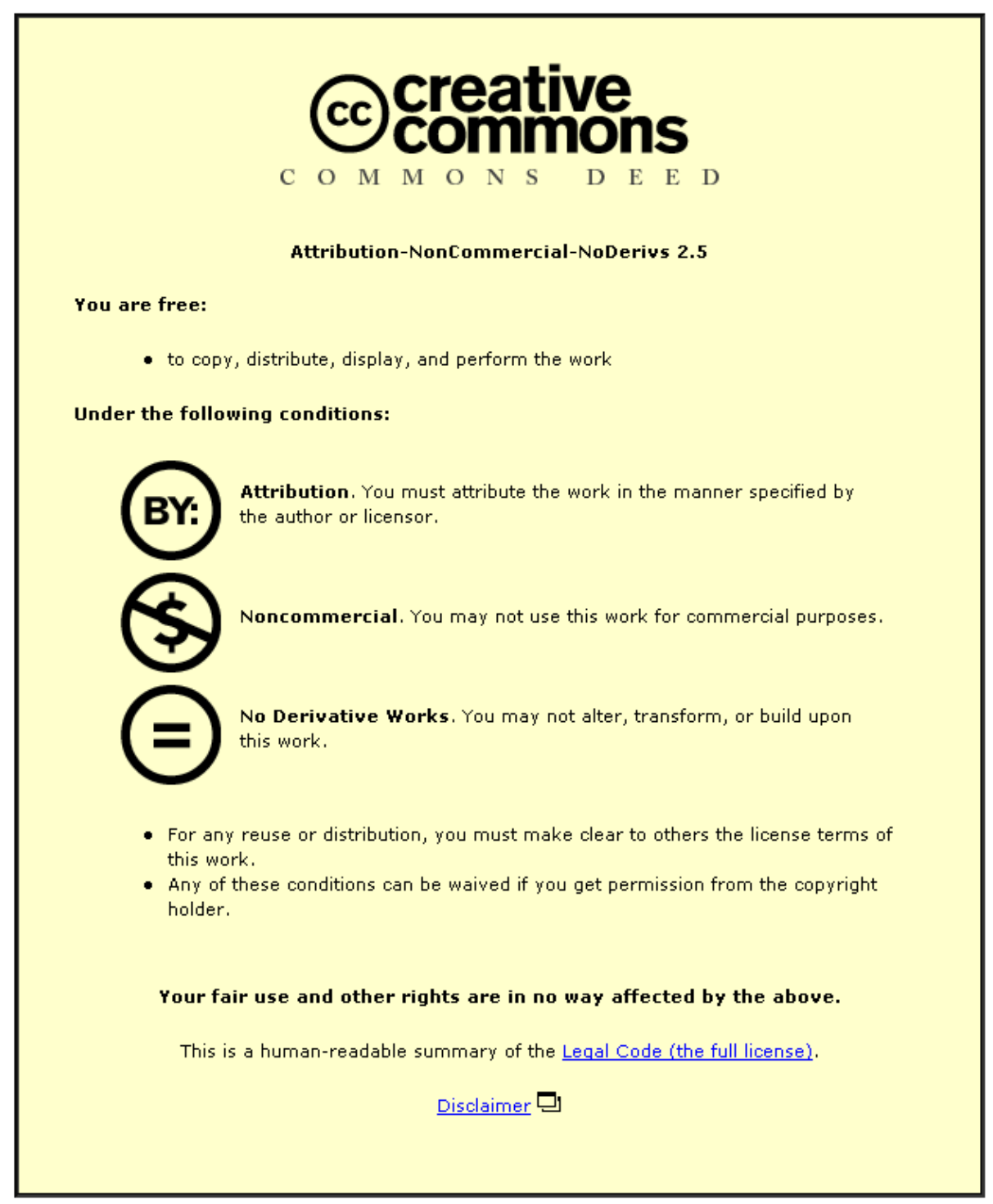

For the full text of this licence, please go to: http://creativecommons.org/licenses/by-nc-nd/2.5/ 


\title{
Elastohydrodynamics of Hypoid Gears in Axle Whine Conditions
}

\author{
Author, co-author (Mahdi Mohammadpour, Stephanos Theodossiades and Homer \\ Rahnejat) \\ Affiliation (Wolfson School of Mechanical and Manufacturing Engineering, Loughborough University, Loughborough, UK)
}

Copyright $\odot 2012$ SAE International

\begin{abstract}
This paper presents an investigation into Elastohydrodynamic (EHL) modeling of differential hypoid gears that can be used in coupling with Newtonian (or multibody) dynamics to study Noise, Vibration and Harshness (NVH) phenomena, such as axle whine. The latter is a noise of a tonal nature, emitted from differential axles, characterised by the gear meshing frequency and its multiples. It appears at a variety of operating conditions; during drive and coasting, high and low torque loading. Key design targets for differential hypoid gears are improved efficiency and reduced vibration, which depend critically on the formation of an EHL lubricant film. The stiffness and damping of the oil film and friction generated in the contact can have important effects and cannot be neglected when examining the NVH behaviour of hypoid gears.

The operating conditions in hypoid gears are usually characterized by high load, relatively low speeds, angled flow and elliptical contact footprint of high aspect ratio. Some extrapolated/empirical equations to estimate friction and film thickness have been reported for moderate loads. However, their use in hypoid gears is questionable. Additionally, the majority of reported numerical models for film thickness and friction have not been applied under such operating conditions. In this paper a numerical model of EHL elliptical point contact has been presented to obtain the EHL film behaviour under the usual range of operating conditions of hypoid gears. Realistic engine torque-speed characteristics are used. For these conditions, the load share per teeth pair contact is in the region of $500-6000 \mathrm{~N}$. A suitable method of solution is applied to ease the convergence of the numerical method, namely the distributed line low relaxation effective influence Newton-Raphson method. As the result of the angled direction of the entraining flow in the contact of hypoid gear teeth pairs, this method has been found to be suitable, thus adopted. The geometric and kinematic input data for EHL calculations are calculated using Tooth Contact Analysis (TCA).
\end{abstract}

\section{INTRODUCTION}

$\mathrm{NVH}$ of automotive gears is considered as an important quality issue, which can be perceived by vehicle occupants regardless of their levels of driving experience. Such problems tend to appear at the final stages of vehicle development, usually requiring cost intensive palliation. Consequently, there is a great need to provide powertrain designers with powerful simulation tools which would enable them to predict $\mathrm{NVH}$ issues and track the key parameters numerically or analytically in the earlier stages of prototype development. A common cause behind gear noise is the fluctuations of transmission input speed, because of the engine torque variations (the combustion process and inertial imbalance introducing engine order vibrations [1]). These fluctuations initiate vibrations within the growling-sound frequency range. A number of publications have been reported on the dynamics of parallel axis transmissions, such as that by Ozguven et al. [2]. However, a relatively small number of investigations can be found on the dynamics of non-parallel axis gears (such as hypoid and bevel gears) because of the complexity of gear kinematics and meshing characteristics. Remmers [3] studied the mass-elastic model of rear axle gears with infinite mesh stiffness to predict the pinion resonance. Donley et al. [4] developed a dynamic model of a hypoid gear for use in finite element analysis of gearing systems. A review of the various gear mechanical models has been given by Ozguven and Houser [5], identifying the main issues affecting the simulation of transmission systems. The main source underlying the appearance of the axle whine lies in the gear meshing process and design characteristics (static transmission error), affecting the teeth mesh stiffness variation. Whine noise is also highly affected by the elasticity of pinion/crown gears as well as any (angular) misalignments. Gear impacting surfaces act as lubricated conjunctions rather than the usually reported dry impacting solids. Rahnejat [6] has used the equivalent meshing stiffness of elastic bodies and the film thickness in elastohydrodynamic contacts. Theodossiades et al. [7] have used a hydrodynamic lubrication model for modeling of gear rattle problem at light and under hydrodynamic regime of lubrication. The hypoid gear teeth pairs form elliptical contact footprints and are often subject to high loads of the order of several $\mathrm{kN}$.

Studies of elliptical point contacts commenced after the pioneering paper on elastohydrodynamic lubrication (EHL) by Grubin [8], based on his work with Ertel [9]. Grubin ignored the side leakage from the contact, requiring a correction factor which has been

Page 1 of 11 
described by Gohar [10]. Numerical work on EHL was first undertaken by Dowson and Higginson [11]. The volume of simulation results undertaken ever since has yielded extrapolated oil film thickness formulae. The early contributions include those of Hamrock and Dowson [12]. There are a number of shortcomings associated with these formulae. Firstly, the range of operating parameters used (such as load and speed based on the original simulated results) is somewhat limited due to difficulties in computation resources and stability of formulation method and solution at the time. Secondly, the earlier analyses excluded certain salient practical features, such as inlet boundary starvation/lubricant flow at an angle to the elliptical contact footprint, all of which are essential for estimation of the lubricant film thickness in hypoid gear teeth pair contacts. With regard to the directional lubricant flow into an elliptical point contact conjunction, Mostofi and Gohar [13] provided numerical predictions, as well as extrapolated film thickness equations for both the central flat and the minimum exit constriction films.

In gear applications and especially in hypoid gears, it is necessary to compute the principal radii of curvature of the pinion and gear wheel teeth through mesh. One method of achieving this is by employing tooth contact analysis (TCA). The method is outlined in detail by Litvin and Fuentes [14]. The current work uses TCA (based on the approach of Mohammadpour et al. [15]). This is to obtain the instantaneous contact geometry, sliding velocity and load share per teeth pair for simultaneous meshing of 1-3 pairs of teeth in a hypoid gear pair of a light truck differential. These are input to an isothermal EHL solution of hypoid gear teeth contacts. Realistic engine torque-speed characteristics are used. For these conditions, the load share per teeth pair contact is in the region of 500-6000N. Therefore, a suitable method of solution is the distributed line low relaxation effective influence Newton-Raphson method. This method was used for ball bearings by Jalali-Vahid et al [16] and for elliptical contacts with angled flow, but in both cases for moderate loads. The same model has been used in a hypoid gear application by Mohammadpour et al. [15] for film thickness investigations only. This was the first reported model for hypoid EHL film calculations using realistic conditions; angled flow and elliptical point contact assumption (considering side leakage). In the current work, the teeth flank friction is also calculated because of its expected influence on gear dynamics and noise. The numerical EHL tool developed can be coupled to a dynamic model of hypoid gear pairs to study their behaviour during high loading (which is often the case in axle whine conditions). Finally, some discussion on the potential interactions/coupling between EHL and dynamic models is presented.

\section{METHODOLOGY}

The method used is a two stage process, combining TCA and EHL analyses. The former determines the number of teeth pairs in contact at any instant of time, their principal radii of curvature at the point of contact, the elastostatic elliptical contact footprint, surface velocities and load share for any conjugate mating teeth pair. An example of the footprint shape obtained at this stage of analysis is illustrated in Figure 1. These form the input to the elastohydrodynamic analysis.

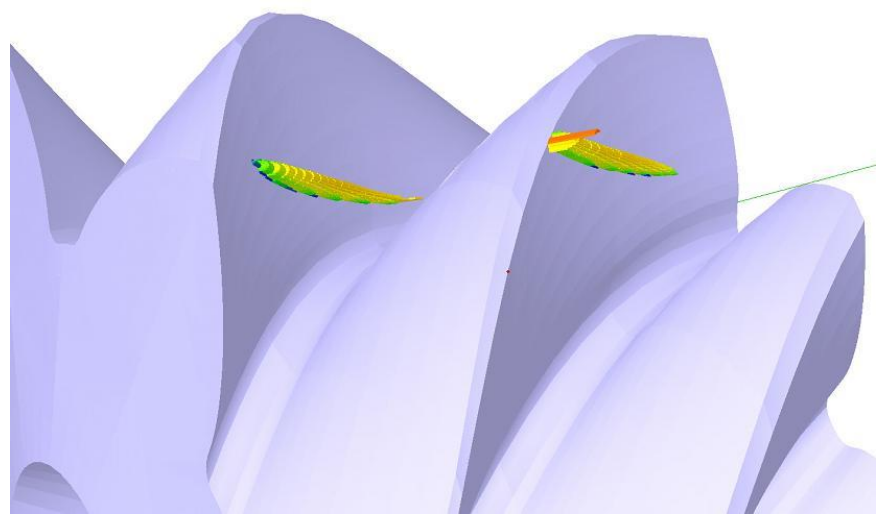

Figure 1: Footprint geometry obtained by TCA

Pressures generated in a lubricated conjunction are obtained through use of Reynolds equation. The form of equation suitable for lubricant entrainment at any angle $\theta$ to the minor axis of an elliptical contact footprint is (Figure 2):

$\frac{\partial}{\partial x}\left[\frac{\rho h^{3}}{\eta} \frac{\partial p}{\partial x}\right]+\frac{\partial}{\partial y}\left[\frac{\rho h^{3}}{\eta} \frac{\partial p}{\partial y}\right]=6 U\left\{\cos \theta \frac{\partial}{\partial x}[\rho h]+\sin \theta \frac{\partial}{\partial y}[\rho h]\right\}$

The speed of entraining motion of the lubricant $U$ through the contact is considered to be constant at any instant of time. This is a transient effect, which often increases the load carrying capacity of the contact as noted by Gohar and Rahnejat [17]. 


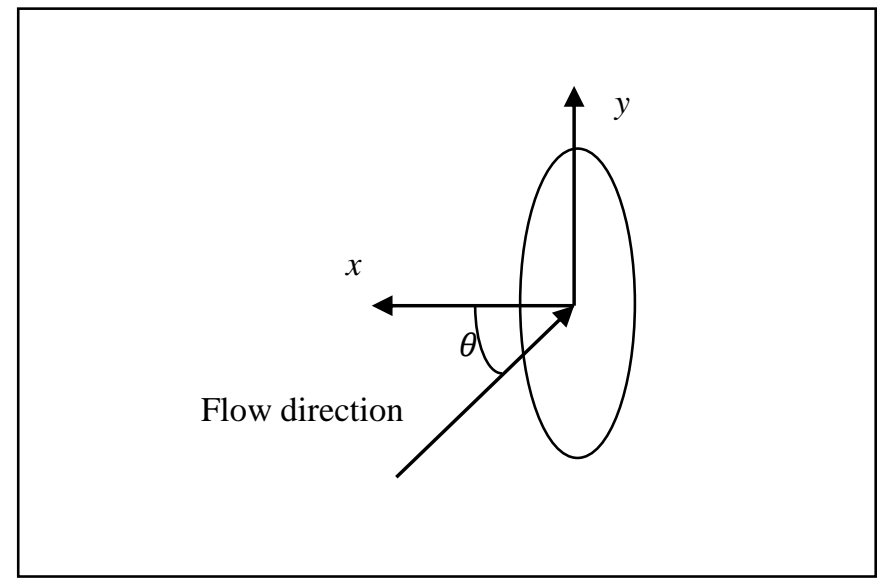

Figure 2: Representation of an elliptical point contact conjunction with angled entrainment flow

The film thickness at any spatial location within the contact domain is given by:

$h(x, y)=h_{c 0}+s(x, y)+\delta(x, y)$

where $\mathrm{s}(\mathrm{x}, \mathrm{y})$ is the un-deformed parabolic conjunctional profile. The localized contact deflection $\delta(x, y)$ is obtained by the solution of the elasticity potential integral:

$\delta(x, y)=\frac{1}{E_{r}} \iint_{A} \frac{p\left(x_{1}, y_{1}\right) d x_{1} d y_{1}}{\sqrt{\left(x-x_{1}\right)^{2}+\left(y-y_{1}\right)^{2}}}$

where $(x, y)$ represents a point where deflection of the semi-infinite elastic half-space of reduced elastic modulus $E_{r}$ is calculated due to any arbitrary pressure distribution $p\left(x_{1}, y_{1}\right)$. To obtain a solution to the EHL problem, comprising equations (1)-(3), the lubricant rheological state is required. For piezo-viscous lubricant behavior [18]:

$\eta=\eta_{0} \exp \left\{\left[\left(\ln \eta_{0}+9.67\right) \times\left(1+5.1 \times 10^{-9} p\right)^{Z}\right]-\left[\ln \eta_{0}+9.67\right]\right\}$

Where:

$Z=\frac{\alpha c_{p}}{\left(\ln \eta_{0}+9.67\right)}=\frac{\alpha}{5.1 \times 10^{-9}\left(\ln \eta_{0}+9.67\right)}$, as $c_{p}=1.96 \mathrm{MPa}$

The lubricant density is given by [11]:

Page 3 of 11 
$\rho=\rho_{0}\left(1+\frac{0.6 \times 10^{-9} p}{1+1.7 \times 10^{-9} p}\right)$

The Reynolds equation is discretised using finite differences in the same manner as described by Jalali-Vahid et al [16]. The solution for pressure at any nodal position $(i, j)$ with a sufficient computation grid covering the entire solution domain is based on the low line relaxation effective influence Newton-Raphson method with Gauss-Seidel iterations. The iterative process comprises the following steps:

1- At each pinion angle, an initial guess is made for the central oil film thickness, using equation (2). The data for contact geometry, load and speed of entraining motion required for this purpose are obtained through TCA.

2- Using the film thickness obtained in step 1, the computational grid domain can be obtained. It is a common approach to assume fully flooded inlet boundary condition in the numerical analysis of EHL problems. In order to ensure this, the following conditions should be met:

$x \rightarrow-\infty, p \rightarrow 0 \quad$ and $\quad y \rightarrow-\infty, p \rightarrow 0$

This means that the inlet boundary should be set at a suitable distance from the leading edge of the elliptical contact footprint.

3- The pressure distribution and the corresponding lubricant film contour are obtained by simultaneous solution of equations (1)-(5) in an iterative manner, where two convergence criteria should be satisfied.

4- The first criterion seeks to compute nodal pressures within a specified limit:

$\sum_{i} \sum_{j}\left|\frac{p_{i, j}^{k}-p_{i, j}^{k-1}}{p_{i, j}^{k}}\right| \leq \varepsilon_{p}$

where, $10^{-5} \leq \varepsilon_{p} \leq 10^{-4}$. If the criterion is not satisfied, the generated pressures are under-relaxed as $p_{i . j}^{k}=p_{i, j}^{k-1}+\Omega \Delta p_{i, j} \in i, j$.

The under-relaxation factor is usually $0.01 \leq \Omega \leq 0.8$ and the steps $3-4$ are repeated.

5- The second criterion seeks to converge the integrated pressure distribution (i.e. lubricant reaction, W) with the instantaneous load share of a contacting teeth pair through mesh, $F$. Recall that at any instant of time between 1-3 pairs of teeth are in $\underline{\text { simultaneous mesh in the case of the differential hypoid gear pair investigated here. The lubricant reaction is }}$

$$
W=\iint p d x d y
$$

Thus, the load convergence criterion is $\left|\frac{F-W}{F}\right| \leq \varepsilon_{w}$

where, $0.001 \leq \varepsilon_{w} \leq 0.05$. If the criterion is not met, the central film thickness, $h_{c o}$, is adjusted and the entire iterative process is repeated:

$h_{c 0}^{l}=h_{c 0}^{l-1}\left(\frac{F}{W}\right)^{\varsigma}$

where, $-0.1 \leq \varsigma \leq 0.1$ is termed a damping factor. 
In the above process, the indices $i, j$ refer to a computational grid position, $k$ denotes the pressure convergence iteration counter and $l$, the load convergence iteration counter.

When both the convergence criteria are met, the pinion angle is advanced within the meshing cycle and the entire process is repeated. To observe the contact conditions for any pair of meshing teeth, the meshing cycle is sub-divided into 20 discrete steps of the pinion angle rotation.

The geometric, kinematic and load data required for the EHL analysis can be obtained from TCA analysis. A similar method to that reported in reference [15] has been utilized in this work. The specifications for the face-hobbed and lapped hypoid gear pair in this study are provided in table 1 , as well as the mechanical properties of the contacting surfaces and rheological properties of the lubricant. The results of TCA are provided in Table 2.

Table 1: Gear pair parameters and properties of contacting solids and the Lubricant

\begin{tabular}{|c|c|c|c|c|c|}
\hline \multicolumn{2}{|c|}{ Pinion parameters: } & \multicolumn{2}{|c|}{ Gear parameters: } & \multicolumn{2}{|c|}{ Material and lubricant properties } \\
\hline $\begin{array}{l}\text { Number of pinion } \\
\text { teeth }\end{array}$ & 13 & Number of gear teeth & 36 & $\begin{array}{l}\text { Pressure viscosity } \\
\text { coefficient }(\alpha)[\mathrm{Pa}-1]\end{array}$ & $2.6 \times 10-8$ \\
\hline $\begin{array}{l}\text { Pinion face-width } \\
(\mathrm{mm})\end{array}$ & 33.851 & Gear face width (mm) & 29.999 & $\begin{array}{l}\text { Atmospheric dynamic } \\
\text { viscosity }\left(\eta_{0}\right)[\mathrm{Pa}-\mathrm{s}]\end{array}$ & 0.135 \\
\hline $\begin{array}{c}\text { Pinion face angle } \\
(\mathrm{deg})\end{array}$ & 29.056 & Gear face angle (deg) & 59.653 & $\begin{array}{l}\text { Inlet density } \rho_{0} \\
{[\mathrm{~kg} / \mathrm{m} 3]}\end{array}$ & 846 \\
\hline $\begin{array}{l}\text { Pinion pitch angle } \\
\text { (deg) }\end{array}$ & 29.056 & Gear pitch angle (deg) & 59.653 & $\begin{array}{l}\text { Modulus of elasticity } \\
{[\mathrm{GPa}]}\end{array}$ & 210 \\
\hline $\begin{array}{l}\text { Pinion root angle } \\
(\mathrm{deg})\end{array}$ & 29.056 & Gear root angle (deg) & 59.653 & $\begin{array}{l}\text { Poisson's ratio of } \\
\text { contacting solids }\end{array}$ & 0.3 \\
\hline $\begin{array}{c}\text { Pinion spiral angle } \\
\text { (deg) }\end{array}$ & 45.989 & Gear spiral angle (deg) & 27.601 & & \\
\hline $\begin{array}{l}\text { Pinion pitch apex } \\
(\mathrm{mm})\end{array}$ & -9.085 & Gear pitch apex (mm) & 8.987 & & \\
\hline $\begin{array}{c}\text { Pinion face apex } \\
(\mathrm{mm})\end{array}$ & 1.368 & Gear face apex (mm) & 10.948 & & \\
\hline $\begin{array}{l}\text { Pinion Outer cone } \\
\text { distance }(\mathrm{mm})\end{array}$ & 83.084 & $\begin{array}{l}\text { Gear Outer cone } \\
\text { distance }(\mathrm{mm})\end{array}$ & 95.598 & & \\
\hline Pinion offset $(\mathrm{mm})$ & 24.0000028 & Gear offset (mm) & 24 & & \\
\hline Pinion hand & Right & & & & \\
\hline
\end{tabular}

Table 2: Equivalent geometry, load share and kinematics of a teeth pair through mesh

\begin{tabular}{|c|c|c|c|}
\hline $\begin{array}{c}\text { pinion } \\
\text { angle } \varphi \\
{[\mathrm{Rad}]}\end{array}$ & $\begin{array}{c}\text { Magnitude } \\
\text { of } \\
\text { Contact load } \\
F_{[\mathrm{N}]}\end{array}$ & $\begin{array}{c}\text { velocity } \\
\text { [m/s] }\end{array}$ & $\begin{array}{c}\text { Velocity along } \\
\text { the minor axis } \\
U \sin \theta_{[\mathrm{m} / \mathrm{s}]}\end{array}$ \\
\hline 0.503 & 744.5 & 18.04 & 7.98 \\
\hline 0.581 & 1700.4 & 17.61 & 8.11 \\
\hline 0.675 & 2716.0 & 17.12 & 8.30 \\
\hline 0.770 & 3944.3 & 16.65 & 8.51 \\
\hline 0.864 & 5343.6 & 16.21 & 8.74 \\
\hline 0.958 & 5764.1 & 15.80 & 8.98 \\
\hline 1.052 & 4542.1 & 15.41 & 9.24 \\
\hline 1.147 & 3554.6 & 15.04 & 9.50 \\
\hline 1.241 & 2363.3 & 14.70 & 9.78 \\
\hline 1.335 & 939.2 & 14.39 & 10.06 \\
\hline pinion & Velocity along & Equivalent & Equivalent \\
\hline
\end{tabular}

Page 5 of 11 


\begin{tabular}{|c|c|c|c|}
\hline $\begin{array}{c}\text { angle } \\
{[\mathrm{Rad}]}\end{array}$ & $\begin{array}{c}\text { the major axis } \\
U \cos \theta_{[\mathrm{m} / \mathrm{s}]}\end{array}$ & $\begin{array}{c}\text { radius } \\
R_{z x}[\mathrm{~m}]\end{array}$ & radius $R_{z y}[\mathrm{~m}]$ \\
\hline 0.503 & 16.18 & 0.0157 & 1.0067 \\
\hline 0.581 & 15.63 & 0.0160 & 1.0626 \\
\hline 0.675 & 14.97 & 0.0164 & 1.1228 \\
\hline 0.770 & 14.31 & 0.0168 & 1.1754 \\
\hline 0.864 & 13.65 & 0.0174 & 1.2204 \\
\hline 0.958 & 12.99 & 0.0180 & 1.2578 \\
\hline 1.052 & 12.33 & 0.0186 & 1.2876 \\
\hline 1.147 & 11.66 & 0.0194 & 1.3098 \\
\hline 1.241 & 10.98 & 0.0202 & 1.3243 \\
\hline 1.335 & 10.29 & 0.0211 & 1.3313 \\
\hline
\end{tabular}

\section{RESULTS AND DISCUSSION}

The current analysis investigates the contact conditions for a moderate to highly loaded hypoid gear pair of a light truck (table 2). The results presented correspond to the interaction of a gear teeth pair though a meshing cycle, during which 1-3 teeth pairs carry the transmitted torque. The results correspond to an engine torque of $175 \mathrm{Nm}$ at $1852.5 \mathrm{rpm}$. Table 2 lists the variation in the load share for a contacting teeth pair through mesh, as well as the effective radii of curvature of an equivalent ellipsoidal solid contacting a semiinfinite elastic half-space of reduced elastic modulus $E_{r}$. It also lists the speed of entraining motion of the lubricant into the contact along the minor and major axes of the Hertzian elastostatic contact ellipse. These parameters constitute the input for the elastohydrodynamic analysis.

Figures 3 and 4 show the pressure distribution and the corresponding oil film thickness contours at the pinion angles 0.864 rad (around the middle of a teeth pair mesh contact), almost corresponding to the instant of maximum contact load and at $1.335 \mathrm{rad}$ (at the end of contact - moderate load conditions) (see also Table 2). The contour of minimum film thickness occurs at the exit constriction. Both cases show an asymmetrical oil film contour because of the angled lubricant flow into the contact with significant side leakage along the major axis of the elliptical footprint. Therefore, the island of minimum film thickness differs from the characteristic horse-shoe constriction when the flow is along the minor axis of the ellipse in EHL contacts of (for example) ball bearings. With a ten-fold increase in load, the film thickness is hardly altered, but the secondary pressure peak region is less pronounced and has moved further towards the exit constriction.

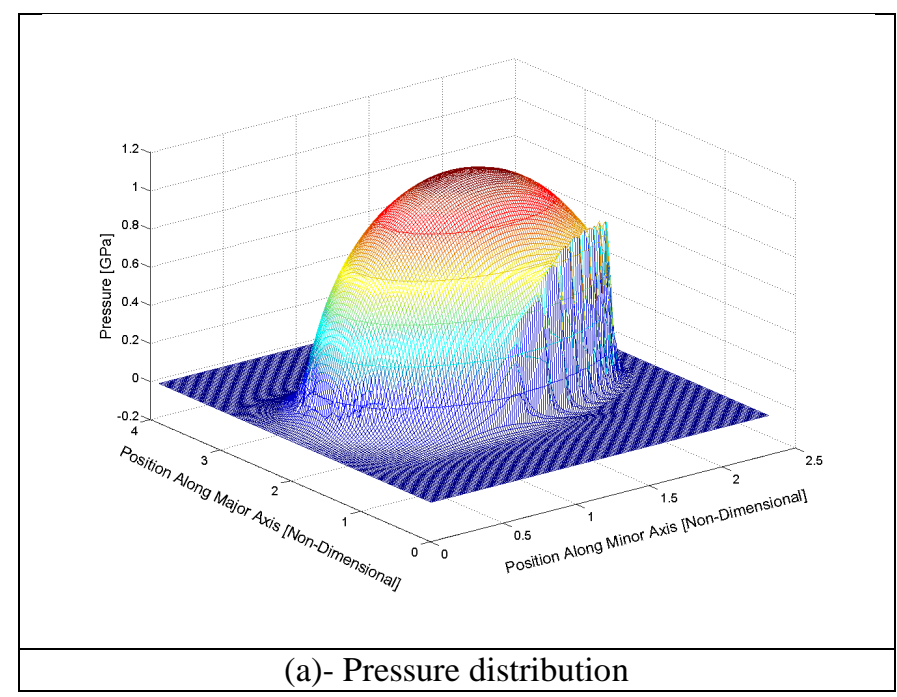

Page 6 of 11 


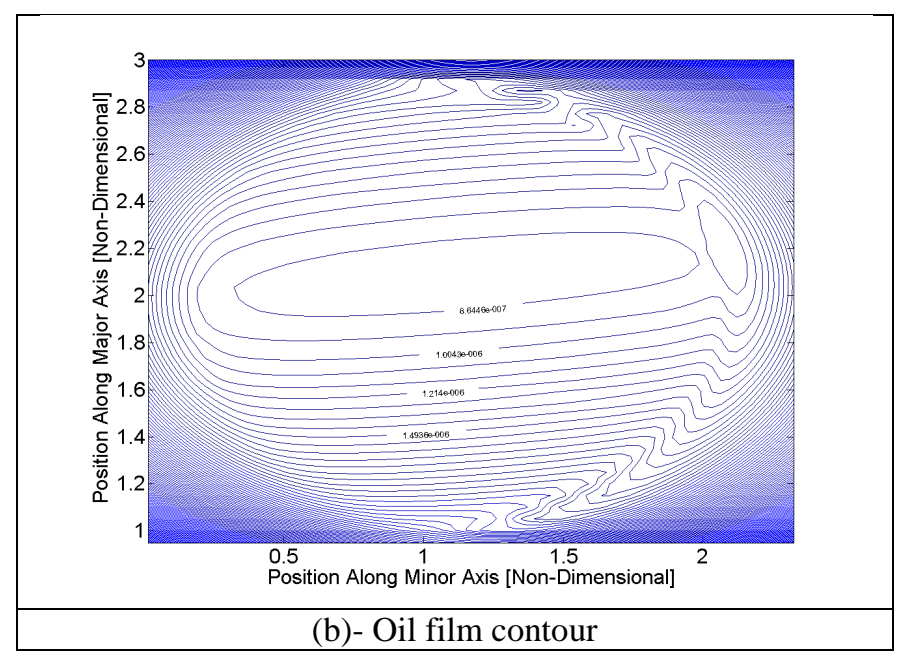

Figure 3: Pressure distribution and oil film contour at maximum contact load (pinion angle of 0.864 in Table 2)

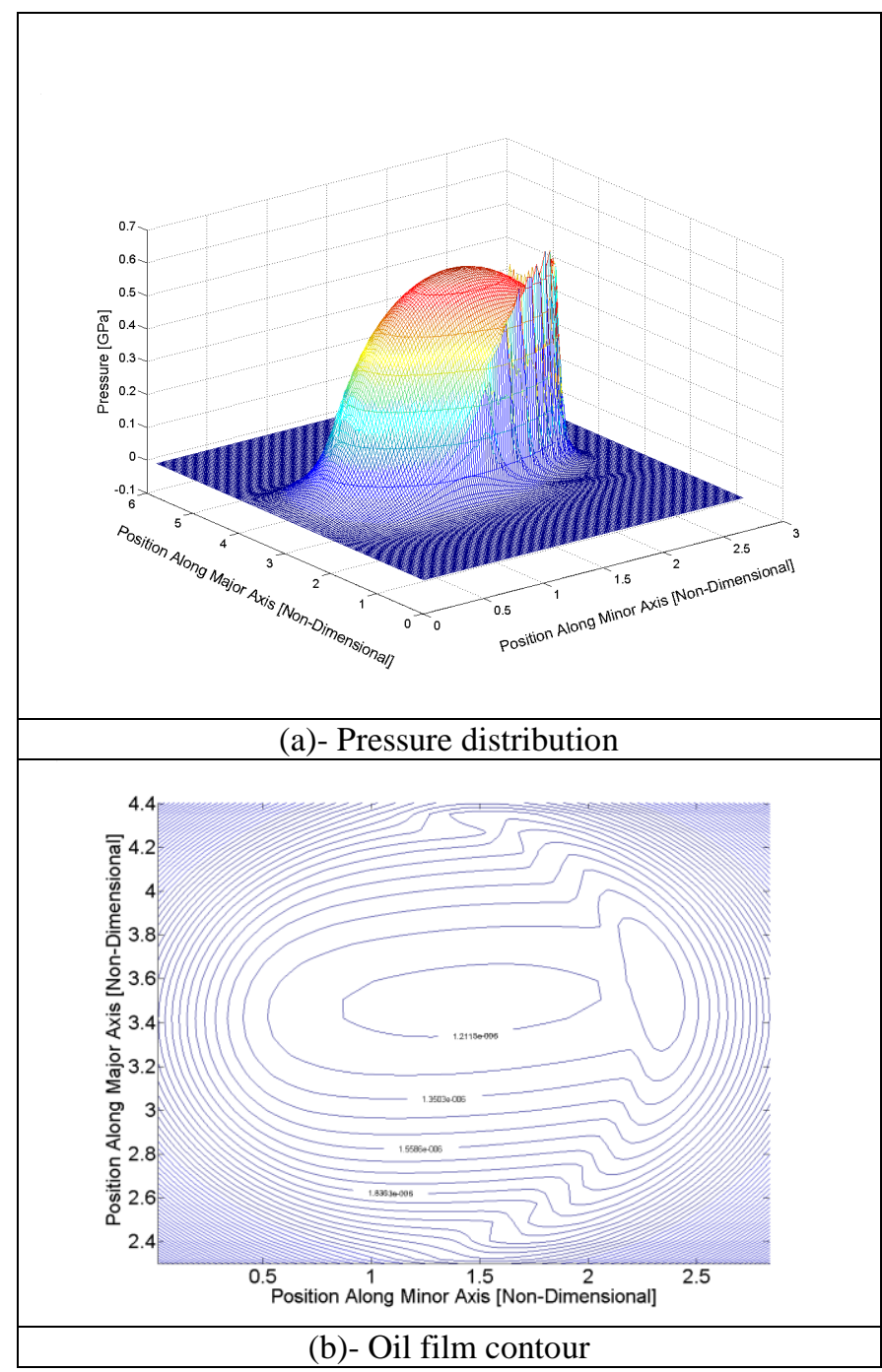

Figure 4: Pressure distribution and oil film contour at the end of the teeth pair mesh with moderate load (pinion angle of 1.335 in Table 2 )

Page 7 of 11 
The maximum pressures reached are around $1.2 \mathrm{GPa}$, even with loads in the order of $6 \mathrm{KN}$. This is because the hypoid gear pair teeth geometry is partially conforming, promoting a larger contact area than for spur or helical gears. Thus, an assumed one dimensional solution would lead to prediction of much higher pressures than it is the case in reality. As already noted the film thickness is almost unaffected by large variation in contact load. For the case presented here the minimum film thickness remains around $0.9-1.1 \mu \mathrm{m}$, which is well in excess of the composite root mean square surface roughness of the contiguous bodies in contact. The isothermal solution here predicts no direct surface interactions, since the surface roughness of modern superfinished hypoid gear teeth is in the range $0.1-0.3 \mu m[19-22]$. With lower speeds of entraining motion and similarly high loads encountered, worst tribological conditions are usually expected. The results described in this paper correspond to driving conditions that can often result in the axle whine phenomenon. Additionally, viscous shear of the lubricant generates heat, reducing its effective viscosity. In many cases this reduces the film thickness and can promote mixed regime of lubrication.

Figure 5 shows the variation of predicted central and minimum film thickness, both being around $0.9 \mu \mathrm{m}$. The figure also shows the predicted values when employing Grubin's equation [8] and those of Chittenden et al [23]. Whilst predictions using the oil film thickness formulae follow similar trends to the numerical predictions, they actually over-estimate the film thickness value. This is because the equations do not apply to the ranges of load and speed parameters that are typical of differential hypoid gears. Another reason is that fully flooded condition (well beyond the starvation boundary) is implicit in the reported equations. In fact, it is generally thought that in practice most gearing systems are rather starved.

Figure 6 shows the friction coefficient variation during meshing cycle. This is calculated using equation (6) below. The predicted values of figure 6 represent the average at any instantaneous contact during gear pair meshing.

$\mu=\frac{1}{W} \int_{\mathrm{A}} \tau \mathrm{dA}$

where

$\tau=\frac{h}{2} \frac{\partial p}{\partial x}+\frac{\eta\left(U_{1}-U_{2}\right)}{h}$

A disadvantage is that the calculated shear stress is viscosity dependent and, consequently, it can be very high using the Newtonian fluid model. This is because of the non-Newtonian behavior of the fluid at high pressures. Most experimental investigations show that the shear stress cannot exceed a certain limit value [24]. This value is pressure dependent and it can be obtained using equation (8). Therefore, when the shear stress exceeds this limiting value, equation (8) should be used instead of equation (7). In this equation, the dimensionless constants $\tau_{L 0}$ and $\lambda$ are equal to $2.3 \mathrm{MPa}$ and 0.047 , respectively.

$\tau_{L}=\tau_{L 0}+\lambda^{\prime} p$

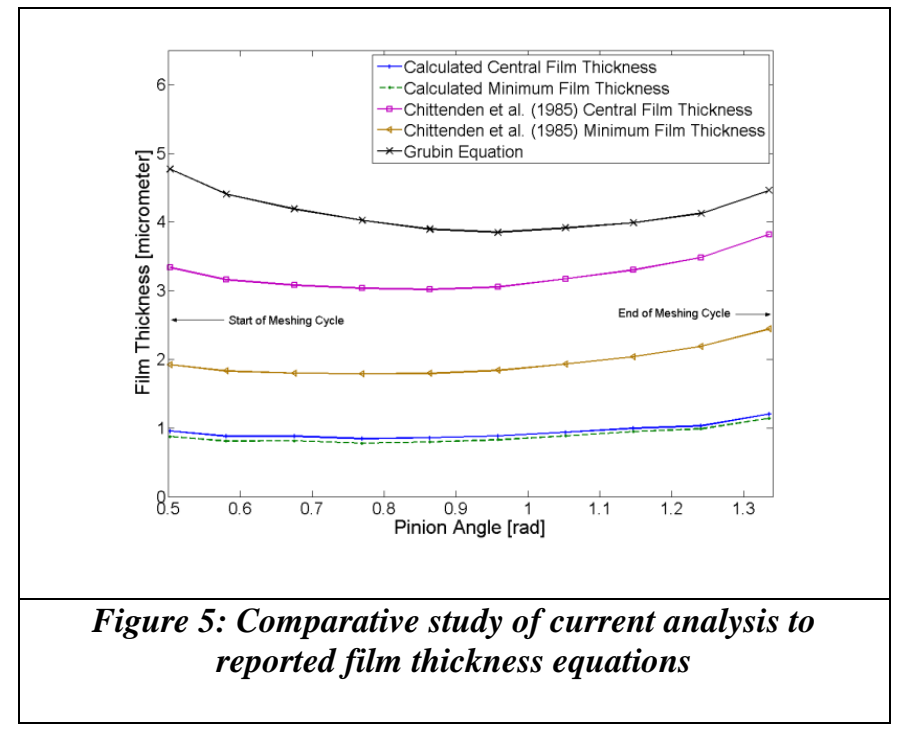

Page 8 of 11 


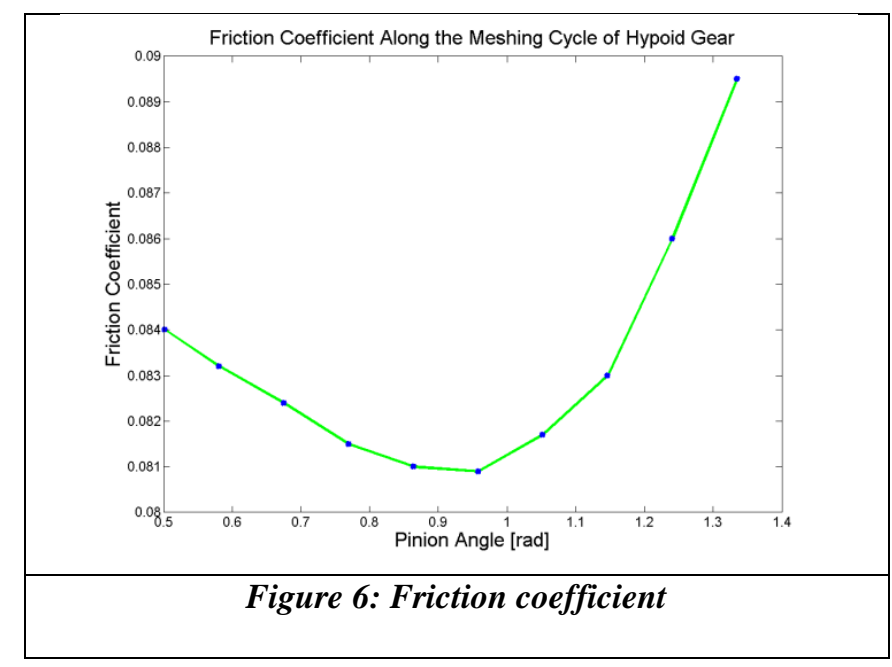

Gear impacting surfaces are treated as lubricated conjunctions rather than the usually reported dry impacting solids. Depending on load and speed of the lubricant's entraining motion into the contact, the regime of lubrication alters. The latter is mainly under elastohydrodynamic conditions. The effect of lubrication is that the effective contact stiffness is the equivalent stiffness of the lubricant film and the elastic teeth members [6]. To calculate this, a film thickness calculation is needed at any instantaneous position during the meshing cycle. As already mentioned, the currently available extrapolated equations are not valid for the case of highly loaded hypoid gears. The presented numerical model is an alternative method, but it is very time consuming to be used directly in dynamic models. To resolve this, a new equation of film thickness should be extrapolated from numerical results. The second effect of the lubricant film is the friction torque generated in engaged gears. Similarly to the film equations, some empirical equations to calculate friction have been reported in literature. However, because of similar reasons, new equations should be extrapolated for this purpose.

\section{SUMMARY/CONCLUSIONS}

The dynamic behaviour of hypoid gears is mostly influenced by lubricated rather than dry contacts. The regime of lubrication is EHL and film thickness and friction have a major role in dynamic applications. These values can be obtained using analytical or extrapolated equations, but because of critical operating conditions, the equations that are valid for other applications with moderate loads cannot be used here. The presented numerical model is able to capture such critical conditions. However, simulations will become extremely time consuming if it is introduced in a gear pair dynamic model. To overcome this, a new extrapolated equation describing the film thickness-load relation should be produced based on the current numerical results of the EHL model. Similarly, a gear teeth friction equation should be extrapolated. These constitute future directions for the current research, as well as including thermal effects between the teeth flanks.

\section{REFERENCES}

1. Rahnejat, H. Multi-body Dynamics: Vehicles, Machines and Mechanisms, PEP (IMechE) and SAE Joint Publishers, 1998

2. Ozguven, H. N. Houser, D. R. 'Dynamic analysis of high speed gears by using loaded static transmission error', Journal of Sound and Vibration 125, 71-83, (1988)

3. Remmers, E., P., Dynamics of automotive rear axle gear noise. SAE Paper 710114, (1971)

4. Donley, M.G. Lim, T.C. Steyer, G.C. 'Dynamic analysis of automotive gearing systems', Journal of Passenger Cars 101 , 77 $87,(1992)$

5. Ozguven, H. N. Houser, D. R. 'mathematical models used in gear dynamics- A review', Journal of Sound and Vibration 121 (3), 383-411 (1988)

6. Rahnejat, H., The Influence of Vibration on the Oil film in Elastohydrodynamic Contacts, PhD Thesis, Imperial College, University of London, 1984.

7. Theodossiades, S. Tangasawi, O. and Rahnejat, H. 'Gear teeth impacts in hydrodynamic conjunctions promoting idle gear rattle', Journal of Sound and Vibration, 303, 632-658, (2007) 
8. Grubin, A.N. " Contact stresses in toothed gears and worm gears", Book 30 CSRI for Technology and Mechanical Engineering , Moscow, DSRI Trans., 337 (1949)

9. Ertel, A.N. Hydrodynamic lubrication based on new principles, Akad. Nauk. SSSR. Prikadnaya Mathematica i Mekhanika, 3(2), 41-52 (1939)

10. Gohar, R. Elastohydrodynamics, Imperial College Press, London (2001)

11. Dowson, D. and Higginson, G.R. "A numerical solution to the elastohydrodynamic problem", Proc. Instn. Mech. Engrs., J. Mech. Engng. Sci., 1, 6-15 (1959)

12. Hamrock, B.J. and Dowson, D. "Isothermal elastohydrodynamic lubrication of point contacts, Part II - Ellipticity parameter results", Trans. ASME, J. Lubn. Tech., 98, 375-383 (1976)

13. Mostofi, A. and Gohar, R. "Oil film thickness and pressure distribution in elastohydrodynamic point contacts", Proc. Instn. Mech. Engrs., J. Mech. Engng. Sci., 24, 171-182 (1982)

14. Litvin, F.L. and Fuentes, A. Gear Geometry and Applied Theory, Second ed., Cambridge University Press, New York (2004)

15. Mohammadpour, M., Theodossiades, S., Rahnejat, H., "Elastohydrodynamic lubrication of hypoid gears.", Journal of Engineering Tribology, IMechE, 2011

16. Jalali-Vahid, D., Rahnejat, H., Gohar, R. and Jin, Z.M "Prediction of oil-film thickness and shape in elliptical point contacts under combined rolling and sliding motion”, Proc. Instn. Mech. Engrs., J. Engng. Trib., 214, 427-437 (2000)

17. Gohar, R. and Rahnejat, H. Fundamentals of Tribology, Imperial College Press, London (2008)

18. Houpert, I. "New results olf traction force calculations in elastohydrodynamic contacts", Trans. ASME, J. Trib., 107, 241$248(1985)$

19. $\mathrm{Xu}, \mathrm{H}$. and Kahraman, A. "Prediction of friction-related power losses of hypoid gear pairs", Proc. Instn. Mech. Engrs, J. Multi-body Dyn., 221, 387-400 (2007)

20. $\mathrm{Xu}, \mathrm{H}$., Kahraman, A., Houser, D.R., "A Model to Predict Friction Losses of Hypoid Gears", AGMA Technical Paper, (2005)

21. Masseth, J., Kolivand, M., "Lapping and Superfinishing Effects on Hypoid Gears Surface Finish and Transmission Errors", Proceedings of the 2007 IDETC/CIE ASME Conference

22. Kolivand, M., Li, S. and Kahraman, A. "Prediction of mechanical gear mesh efficiency of hypoid gear pairs", Mech. \& Mach. Theory, 45, 1568-1582(2010)

23. Chittenden, R. J., Dowson, D., Dunn, J. F. and Taylor, C. M. "A theoretical analysis of the isothermal elastohydrodynamic lubrication of concentrated contacts. II. General Case, with lubricant entrainment along either principal axis of the Hertzian contact ellipse or at some intermediate angle“, Proc. Roy. Soc., Ser. A, 397, 271-294 (1985)

24. Johnson and, K. L., Tevaarwerk, J. L., "Shear Behaviour of Elastohydrodynamic Oil Films", Proc. R. Soc. Lond., 356, 215 236 (1977)

\section{CONTACT INFORMATION}

Dr Stephanos Theodossiades

Wolfson School of Mechanical and Manufacturing Engineering

Loughborough University

Loughborough, Leicestershire, LE11 3TU, United Kingdom

Tel: + 44 (0) 1509227664 Fax: + 44 (0) 1509227648

Email: S.Theodossiades@lboro.ac.uk

\section{ACKNOWLEDGMENTS}

The authors would like to express their gratitude to Dr.Sandeep Vijayakar of Advanced Numerical Solutions Inc. for his assistance and his generosity for supplying the CALYX software.

\section{DEFINITIONS/ABBREVIATIONS}

a : Contact semi-major half-width

b : Contact semi-minor half-width

$E_{p} \quad$ : Young's modulus of elasticity of pinion gear material

$E_{r} \quad$ : Reduced elastic modulus of the contact: $\pi /\left(1-v_{p}^{2} / E_{p}\right)+\left(1-v_{w}^{2} / E_{w}\right)$

Page 10 of 11 


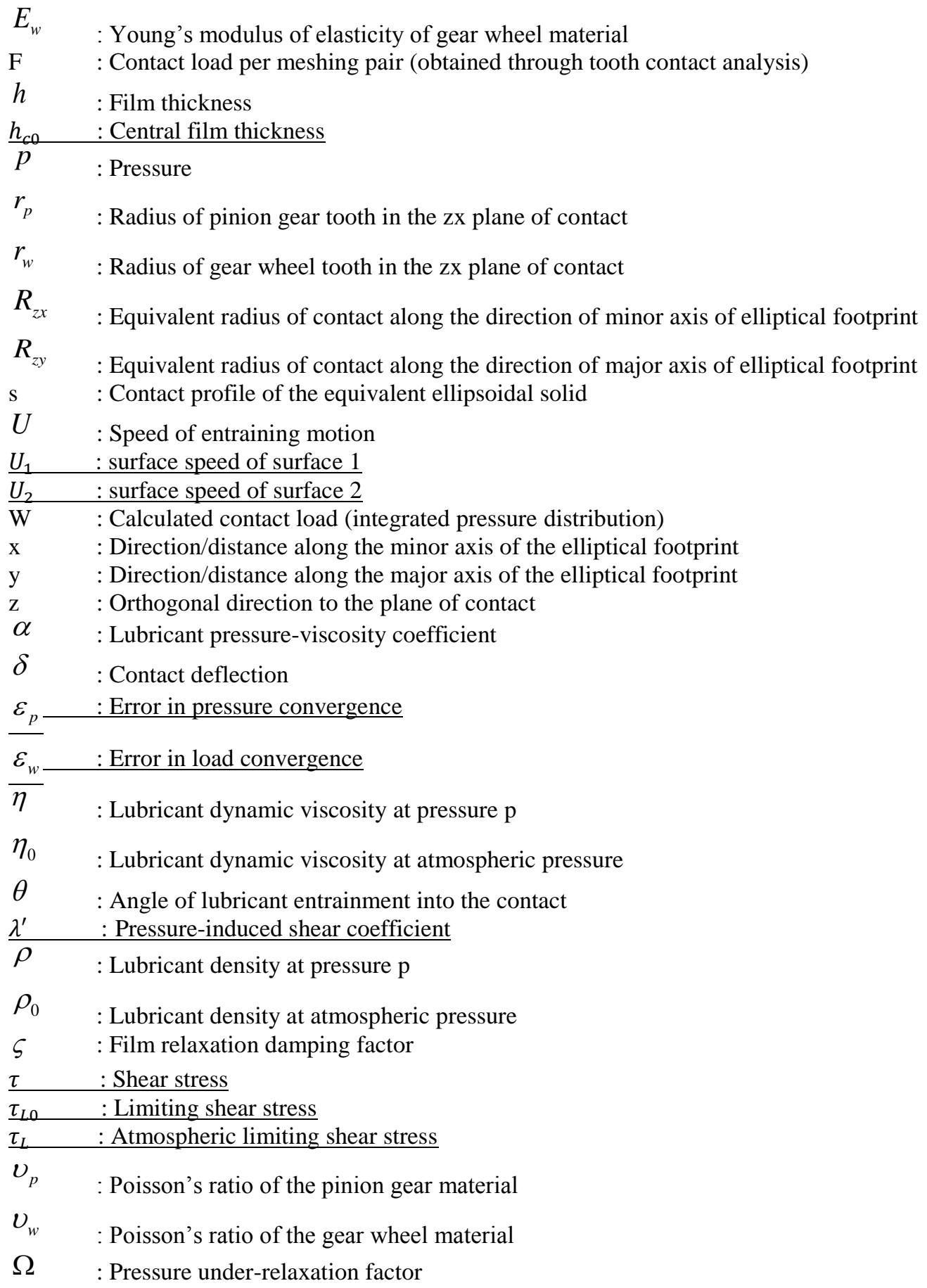

